\title{
Association of chemotactic cytokine receptor 5 (CCR5) gene polymorphism (59029 A/G, rs1799987) with diabetic kidney disease in patients with type 2 diabetes from Poland
}

\author{
Patrycja Pokrzywnicka (101, Hanna Kwiendacz ${ }^{\circledR 1}$ 1, Katarzyna Nabrdalik ${ }^{(1)}$, Weronika Hajzler ${ }^{(1)}$, \\ Piotr Adamczyk ${ }^{\circledR 3}$, Dariusz Moczulski ${ }^{\circledR 4}$, Wanda Trautsolt ${ }^{(10}$, Władysław Grzeszczak ${ }^{+}{ }^{(1)}$, \\ Janusz Gumprecht ${ }^{(10} 1$
}

${ }^{1}$ Department of Internal Medicine, Diabetology and Nephrology, Faculty of Medical Sciences in Zabrze, Medical University of Silesia, Katowice, Poland

${ }^{2}$ Doctoral School, Department of Paediatric Haematology and Oncology, Faculty of Medical Sciences in Zabrze, Medical University of Silesia, Katowice, Poland

${ }^{3}$ Department of Paediatrics, Faculty of Medical Sciences in Katowice, Medical University of Silesia, Katowice, Poland

${ }^{4}$ Department of Internal Medicine and Nephrodiabetology, Medical University of Lodz, Poland

\begin{abstract}
Introduction: Diabetic kidney disease (DKD) pathogenesis is multifactorial and is a combination of metabolic, genetic, and environmental factors. Due to a long period of asymptomatic course, it is often diagnosed late when advanced stages of the disease are present. Among patients with diabetes, the presence of chemotactic cytokine receptor 5 (CCR5) gene polymorphism is suspected to be associated with the risk of DKD occurrence; however, the results of the research conducted so far are inconclusive. The aim of this study was to evaluate the CCR5 gene polymorphism (rs1799987, 59029 A/G) association with DKD among patients with type 2 diabetes mellitus (T2DM), who are residents of the Upper Silesia region of Poland.

Material and methods: CCR5 gene polymorphism (rs1799987, $59029 \mathrm{~A} / \mathrm{G}$ ) was assessed among consecutive patients with type 2 diabetes mellitus (T2DM) treated in a single outpatient diabetology clinic in Upper Silesia, Poland. Its association with DKD was examined. Additionally, selected clinical and demographic data were included in the analysis.

Results: Among 467 eligible study patients, there was no association between examined CCR5 gene polymorphism and the presence of DKD in relation both to the American Diabetes Association definition $(\mathrm{p}=0.6)$ and to the National Kidney Foundation definition $(\mathrm{p}=0.3)$ of this complication.

Conclusion: The presented study did not confirm the association between the examined gene polymorphism and the risk of DKD; further studies in this area are needed in order to establish or explicitly exclude this association. (Endokrynol Pol 2022; 73 (1): 103-109)
\end{abstract}

Key words: diabetes mellitus type 2; diabetic kidney disease; CCR5; gene; polymorphism

\section{Introduction}

Diabetes is the main cause of chronic kidney disease (CKD) and at the same time the leading cause of end-stage renal disease (ESRD) worldwide. It is estimated that up to $30 \%$ of patients with diabetes mellitus type 1 (T1DM) and approximately $40 \%$ of those with diabetes mellitus type 2 (T2DM) will develop diabetic kidney disease (DKD) [1].

The pathogenesis of DKD is multifactorial and consists of metabolic, genetic, and environmental factors, and due to its long period of asymptomatic course, it is often diagnosed when advanced stages of the disease are present [2].To date, there are no universal methods that can select patients who are prone to the occurrence of DKD. Recently, several studies have highlighted the role of chemokines in the pathophysiology of DKD $[3-5,6]$. Chemotactic cytokine receptor 5 (CCR5) takes part in the migration of some T-cells, monocytes, and NK cells towards sites where inflammation takes place; it is also constantly expressed on macrophages and Tlymphocytes. Among the most commonly examined polymorphisms there is a deletion of 32 base pairs (bp) in exon 3 [12]. Of interest, homozygotes presenting this deletion display a strong yet incomplete resistance to human immunodeficiency virus (HIV) infection and, in the case of heterozygotes, delayed progression to acquired immunodeficiency syndrome (AIDS) is observed [13]. Another frequently described polymorphism of the CCR5 gene is the $59029 \mathrm{G} / \mathrm{A}$ polymorphism in the 
promoter region (rs1799987), which causes increased transcriptional activity of the CCR5 gene [11]. To date, outcomes of several studies suggest that the 59029 G/A polymorphism is associated with an increased risk of DKD in patients with T1DM [14-16] and with T2DM [11, 17-23]. There is also a study that failed to confirm this association [11, 14-22]. The CCR5 gene polymorphism has been assessed in many ethnical groups, among others in a group of Polish patients with T1DM [15] and T2DM [19]. We decided to examine the population of T2DM patients inhabiting the Upper Silesia Region in order to confirm the association of CCR5 gene polymorphism (59029A/G, rs1799987) and the risk of DKD.

\section{Material and methods}

Five hundred consecutive T2DM patients treated in the Outpatients Diabetology Clinic in Zabrze, Poland, who fulfilled the inclusion and did not fulfil the exclusion criteria, were invited to take part in this cross-sectional study. Eventually 467 of them took part in the final analysis; the reasons for disqualification of the others are described in the following sections of the manuscript. The pattern of patients' division into the study and control groups was simi- lar to the one we used to examine the association of the ELMO1 (Engulfment and cell motility 1) gene and DKD in our previous study on a different group of patients with T2DM [24]. The inclusion criteria for the current study were as follows: T2DM and the presence (cases) or lack of DKD (controls). We initially divided the study participants into two groups (illustrated in Fig. 1): the study and control group I consisted of T2DM patients with/without DKD diagnosed according to the American Diabetes Association's (ADA) definition. In a subgroup of patients without elevated albumin excretion, there were 31 with eGFR $<60 \mathrm{~mL} / \mathrm{min} / 1.73 \mathrm{~m}^{2}$, but all of them had recurrent infections, and therefore, due to possible bias, they were disqualified from further analysis.

Kidney biopsy is the only certain way to establish whether CKD is caused by DM and can be classified as DKD [25], but this is an invasive method and not used in everyday practice. Therefore, in order to increase the likelihood of a proper diagnosis of DKD, we decided to select a second study and control group (group II) on the basis of the DKD definition proposed by the National Kidney Foundation (NKF).

The exclusion criteria for the study were as follows: age under 18 years, types of diabetes other than T2DM, previously diagnosed neoplastic disease, and diseases that can cause CKD (like chronic glomerulonephritis, chronic interstitial nephritis). The study protocol was approved by the Ethical Committee of the Medical University of Silesia in Katowice (NN-6501-34/05) and was performed in accordance with ethical standards and with the 1964 Helsinki declaration and its later amendments. Also, all eligible patients gave written informed consent to participate in the study.

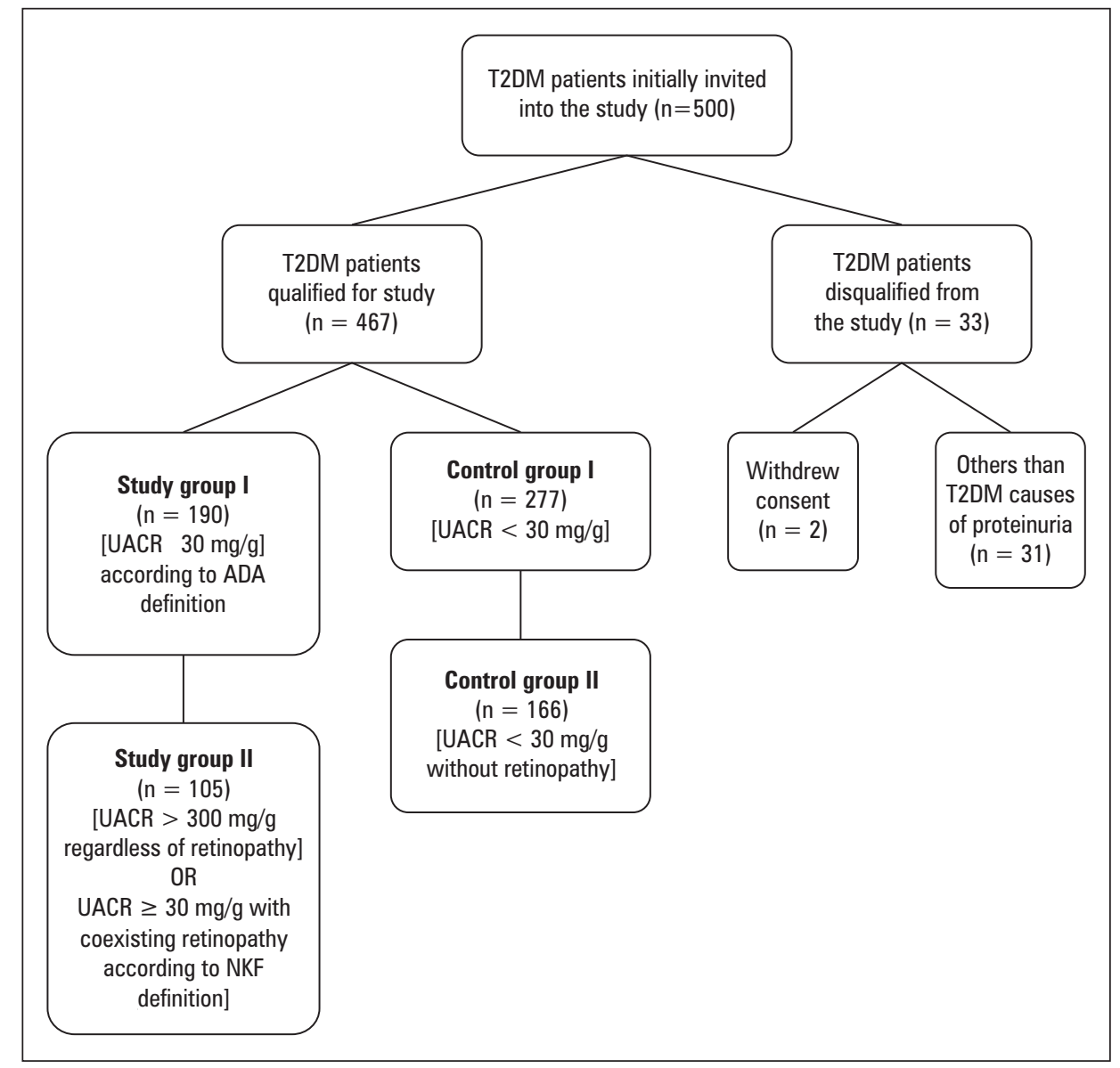

Figure 1. Patients' allocation into study and control groups and reasons for disqualification. T2DM - type 2 diabetes mellitus; UACR — urine albumin-creatinine ratio; American Diabetes Association; NKF — National Kidney Foundation 


\section{Methods}

This was a cross-sectional study including T2DM patients with and without DKD. After written consent was obtained, basic demographic data were collected, and patients' medical histories were established on the basis of available medical records. Data regarding hypertension, smoking status, and concomitant micro and macrovascular diabetic complications was gathered. The urine albumin-creatinine ratio (UACR) value was drawn from the patients' medical history (we analysed outcomes of three morning urine samples collected over the period of six months and estimated UACR using immunoturbidimetric methods). On the same day, anthropometric parameters, i.e. weight $(\mathrm{kg})$ and height $(\mathrm{m})$, were measured by standard methods, and the body mass index (BMI) was calculated as weight divided by height squared (kg/ $\mathrm{m}^{2}$ ). Moreover, blood pressure was measured (after 5 minutes of rest) three times, in a sitting position using a Microlife BP AG1-20 sphygmomanometer, and the first measurement was discarded. On the day of the enrolment, patients had a blood sample drawn in order to have it analysed for haemoglobin $\mathrm{A}_{1 c}\left(\mathrm{HbA}_{1 c}\right)$ and serum creatinine concentration, and for it to be stored for subsequent $\mathrm{SNP}$ genotyping. $\mathrm{HbA}_{1 c}$ was measured using a high-performance liquid chromatography method (HPLC) [26]. Jaffe's method was used to determine serum creatinine concentration [27], and on its basis eGFR was calculated according to the CKD-EPI formula [28]. In a period of 7 days after enrolment for the study, each patient was examined by the same ophthalmologist. In order to determine the presence of diabetic retinopathy a fundus examination in a slit lamp after dilating the pupils was performed.

\section{SNP genotyping}

Genomic DNA was extracted from patients' peripheral blood lymphocytes: $4.9 \mathrm{~mL}$ of venous blood was collected into S-Monovette tubes (Sarstedt, $6.4 \mathrm{mg}$ of potassium EDTA) and centrifuged for 10 minutes (1000 rpm, Sigma 3K15); the buffy coat was aspirated into $2 \mathrm{~mL}$ cryovials and stored at $-20^{\circ} \mathrm{C}$ until DNA isolation. After defrosting, the material was transferred to $50 \mathrm{~mL}$ Falcon tubes (Sarstedt) and erythrocyte lysis buffer was added $(0.32 \mathrm{~mol} / \mathrm{L}$ sucrose, $0.01 \mathrm{mmol} / \mathrm{L}$ TrisHCL, $5 \mathrm{mmol} / \mathrm{L}$ magnesium chloride, and $1 \%$ Triton X-100). After 30 minutes of incubation at $4^{\circ} \mathrm{C}$, the material was centrifuged (10 minutes, $3000 \mathrm{rpm}, 4^{\circ} \mathrm{C}$, Sigma 3K15). The supernatant was removed, and the leukocyte sediment was purified with lysis buffer again as before. DNA was extracted from the leucocyte sediment via a DNAzol Reagent (Life Technologies, USA) in accordance with the manufacturer's instructions. The quality and quantity of DNA was examined with Gen Quant II (Pharmacia Biotech, Sweden). The polymerase chain reaction (PCR) identified base pairs (bp) with an rs1799987 polymorphism. The reaction substrates were as follows: $200 \mathrm{ng}$ DNA, $1.5 \mathrm{mmol} / \mathrm{L}$ magnesium chloride, $0.2 \mathrm{mmol} / \mathrm{L}$ deoxy-nucleoside triphosphates, 20 pmol primer CCR5 F 5'-CCC GTG AGC CCA TAG TTA AAA CTC $-3^{\prime}$, and 20 pmol primer CCR5 R 5'-TCA CAG GGC TTT TCA ACA GTA AGG-3', and 0.5 units of DNA polymerase DyNAzyme TMII (Finnzymes). PCR thermal cycles were as follows: denaturation at $94^{\circ} \mathrm{C}$ for 5 minutes and then 35 cycles: 1 minute at $94^{\circ} \mathrm{C}$, 1 minute at $55^{\circ} \mathrm{C}$, and 1 minute at $72^{\circ} \mathrm{C}$; at the end -10 minutes at $72^{\circ} \mathrm{C}$. Digestion with Bsp1286I restriction enzyme lasted for 2 hours at $37^{\circ} \mathrm{C}$. The PCR product was dispersed via electrophoresis on $2 \%$ agarose gel with ethidium bromide, enabling DNA visualisation in UV. Allele G was in two DNA bands (131 and 136 bp). Allele A had no cutting spot for the enzyme, and the DNA band was $267 \mathrm{bp}$ long. The method was validated in the laboratory. The length of the fragments was estimated in comparison with a $50 \mathrm{bp}$ long DNA Ladder (Fermentas). The results were documented via a ViberLourmet with a UV transilluminator.

\section{Statistical analysis}

In the statistical analysis Microsoft Excel and Statistica 12.0 software (StatSoft Inc., USA) were used. In order to establish the distribution of quantitative variables, the Shapiro-Wilk normality test was used.
For continuous data of normal distribution, descriptive statistics were presented as mean \pm standard deviation (SD). For categorical and qualitative variables, absolute values and percentages were presented. Accordance with Hardy-Weinberg equilibrium (HWE) was tested with Pearson's $\chi^{2}$ test. In order to perform comparative analyses, we used the t-test or Mann-Whitney U-test for variables with normal distribution and other types of distribution, respectively. A $p$ value $<0.05$ was considered to be statistically significant.

\section{Results}

Out of 500 T2DM patients who were invited to participate in the study, 467 meeting the criteria took part in the final analysis. Figure 1 shows patients' allocation into the groups and reasons for disqualification.

Basic demographic and clinical profiles of patients divided into study and control groups are presented in Tables 1 and 2.

The distribution of genotype frequencies of the CCR5 gene polymorphism both in study and control group I and group II was in accordance with the Hardy-Weinberg equilibrium, which is presented in Tables 3 and 4 .

On the basis of $\chi^{2}$ Pearson's test, we established that there was no association between examined CCR5 gene polymorphism and the presence of DKD in the study and control group I (Tab. 3, ADA definition, $\mathrm{p}=0.6$ ) nor in the study and control group II (Tab. 4, NKF definition, $\mathrm{p}=0.3$ ).

\section{Discussion}

In the presented study, we have not proven that there is an association between the CCR5 gene polymorphism (rs1799987, 59029 A/G) and DKD occurrence in patients with T2DM living in the Upper Silesia Region in Poland. There were many studies performed to date examining this single nucleotide polymorphism's (SNP) association with DKD, but the inclusion criteria for the study groups differed between researchers, and none of them used the two available definitions of DKD, namely the one proposed by ADA and a more restricted one by NKF. Some of the studies mentioned below, as well as the $59029 \mathrm{~A} / \mathrm{G}$ polymorphism of the CCR5 gene, also examined a 32-base-pair (32-bp) deletion, but in this discussion we will focus solely on comparing the results considering the exact SNP examined in our study.

Surprisingly, only the results of the study conducted by Pettigrew et al. [16] are in accordance with our findings. The authors examined an association between CCR5 gene promoter polymorphism (rs1799987, 59029 A/G) and the presence of DKD in Irish Caucasian T1DM patients (267 cases with DKD and 442 controls without DKD). DKD was diagnosed on the basis of either UACR $>30 \mathrm{mg} / \mathrm{mmol}$, the presence of renal replacement therapy, or urine protein excretion of 
Table 1. Demographic and clinical profile of study group I and control group I

\begin{tabular}{lccc}
\hline Variable & Study group I (n = 190) & Control group I (n = 277) & p value \\
\hline Age mean \pm SD [years] & $62.0 \pm 8.5$ & $63.0 \pm 8.8$ & $\geq 0.05$ \\
\hline Male [n (\%)] & $84(44.2)$ & $111(40.1)$ & $\geq 0.05$ \\
\hline BMI mean \pm SD [kg/m²] & $29.6 \pm 4.8$ & $29.4 \pm 4.6$ & $\geq 0.05$ \\
\hline T2DM duration time mean \pm SD [years] & $11.7 \pm 7.6$ & $10.5 \pm 7.2$ & $\geq 0.05$ \\
\hline HbA $_{1 c}$ mean \pm SD (\%) & $9.2 \pm 1.9$ & $8.6 \pm 1.7$ & $<0.001$ \\
\hline eGFR mean \pm SD [mL/min/1.73 m²] & $81.4 \pm 25.5$ & $84.3 \pm 22.5$ & $\geq 0.05$ \\
\hline Diabetic retinopathy [n (\%)] & $105(55.3)$ & $111(40.1)$ & $<0.01$ \\
\hline Hypertension [n (\%)] & $168(88.4)$ & $250(90.3)$ & $\geq 0.05$ \\
\hline Macrovascular complications [n (\%)] & $78(41.1)$ & $104(37.6)$ & $\geq 0.05$ \\
\hline Smoker [n (\%)] & $83(43.7)$ & $112(40.4)$ & $\geq 0.05$ \\
\hline Insulin [n (\%)] & $99(52.1)$ & $118(42.6)$ & $<0.05$ \\
\hline Antidiabetic oral drugs [n (\%)] & $83(43.7)$ & $148(53.4)$ & $<0.05$ \\
\hline Exclusively dietary management [n (\%)] & $8(4.2)$ & $11(4.0)$ & $\geq 0.05$ \\
\hline ACEl/ARB [n (\%)] & $89(46.8)$ & $106(38.3)$ & $\geq 0.05$ \\
\hline
\end{tabular}

Data presented as mean $\pm S D$ or numbers of affected patients (percentages). ACEI — angiotensin converting enzyme inhibitors; ARB — angiotensin receptor blockers; $\mathrm{BMI}$ - body mass index; eGFR — estimated glomerular filtration, $\mathrm{HbA}_{1 \mathrm{c}}$ - haemoglobin $\mathrm{A}_{1 \mathrm{c}} ; \mathrm{T} 2 \mathrm{DM}$ - type 2 diabetes mellitus; $\mathrm{n}$ - number of patients; $\mathrm{p}$ - statistical significance; SD — standard deviation

Table 2. Demographic and clinical profile of study and control group II

\begin{tabular}{|c|c|c|c|}
\hline Variable & Study group II $(\mathrm{n}=105)$ & Control group II $(n=166)$ & p value \\
\hline Age mean \pm SD [years] & $62.0 \pm 8.7$ & $62.75 \pm 8.7$ & $\geq 0.05$ \\
\hline Male [n (\%)] & $44(41.9)$ & $67(40.4)$ & $\geq 0.05$ \\
\hline BMI mean $\pm \mathrm{SD}\left[\mathrm{kg} / \mathrm{m}^{2}\right]$ & $29.2 \pm 4.5$ & $29.1 \pm 4.9$ & $\geq 0.05$ \\
\hline T2DM duration time mean \pm SD [years] & $11.2 \pm 7.3$ & $10.6 \pm 7.4$ & $\geq 0.05$ \\
\hline $\mathrm{HbA}_{1 \mathrm{c}}$ mean $\pm \mathrm{SD}(\%)$ & $9.0 \pm 2.0$ & $8.4 \pm 1.6$ & $<0.01$ \\
\hline eGFR mean $\pm \mathrm{SD}\left[\mathrm{mL} / \mathrm{min} / 1.73 \mathrm{~m}^{2}\right]$ & $79.7 \pm 26.4$ & $82.7 \pm 21.8$ & $\geq 0.05$ \\
\hline Diabetic retinopathy [n (\%)] & $105(55.3)$ & $111(40.1)$ & $<0.01$ \\
\hline Hypertension [n (\%)] & $92(87.6)$ & $147(88.6)$ & $\geq 0.05$ \\
\hline Macrovascular complications [n (\%)] & $45(42.9)$ & $68(41.0)$ & $\geq 0.05$ \\
\hline Smoker [n (\%)] & $43(41.0)$ & $68(41.0)$ & $\geq 0.05$ \\
\hline Insulin [n (\%)] & $65(61.9)$ & $49(29.5)$ & $<0.001$ \\
\hline Antidiabetic oral drugs [n (\%)] & $38(36.2)$ & $107(64.6)$ & $<0.001$ \\
\hline Exclusively dietary management [n (\%)] & $2(1.9)$ & $10(6.0)$ & $\geq 0.05$ \\
\hline ACEI/ARB [n (\%)] & $52(49.5)$ & $70(42.2)$ & $\geq 0.05$ \\
\hline
\end{tabular}

Data presented as mean $\pm S D$ or numbers of affected patients (percentages). ACEI — angiotensin converting enzyme inhibitors; ARB — angiotensin receptor blockers; $\mathrm{BMI}$ — body mass index; eGFR — estimated glomerular filtration; $\mathrm{HbA}_{1 \mathrm{c}}$ — haemoglobin $\mathrm{A}_{1 \mathrm{c}} ; \mathrm{T} 2 \mathrm{DM}$ — type 2 diabetes mellitus; $\mathrm{n}$ — number of patients; $\mathrm{p}$ — statistical significance; SD — standard deviation

$>0.5 \mathrm{~g} / 24 \mathrm{~h}$ [29]. Based on the obtained results, researchers concluded that there is no significant association between the above-mentioned SNP and DKD [16].

To the best of our knowledge, there are only two studies that have examined the association between CCR5 gene polymorphism (rs1799987, 59029 A/G) and the presence of DKD performed in Poland [15, 19]. In the study by Buraczynska et al. there were 910 T2DM patients and 596 healthy volunteers as controls. T2DM patients were divided into two groups based on the presence or lack of microangiopathic complications such as neuropathy, retinopathy, and nephropathy. DKD was diagnosed based on albuminuria $\geq 300 \mathrm{mg} / 24 \mathrm{~h}$ in at least two consecutive urine samples. On the basis of performed analyses, it transpired that the frequency of A allele was significantly higher in patients with DKD 
Table 3. Distribution of the genotype frequencies of the CCR5 gene polymorphism (rs1799987, 59029 A/G) in the study and control groups $I$ ( $p=0.6$ on the basis of $\chi^{2}$ Pearson's test)

\begin{tabular}{lcc}
\hline Variable & $\begin{array}{c}\text { Study group I } \\
(\mathbf{n}=\mathbf{1 9 0 )}\end{array}$ & $\begin{array}{c}\text { Control group I } \\
(\mathbf{n}=\mathbf{2 7 7 )}\end{array}$ \\
\hline AA genotype $[n(\%)]$ & $82(43.2)$ & $110(39.7)$ \\
\hline AG genotype $[n(\%)]$ & $79(41.6)$ & $117(42.2)$ \\
\hline GG genotype $[n(\%)]$ & $29(15.3)$ & $50(18.1)$ \\
\hline
\end{tabular}

Data presented as numbers of patients (percentages).

HWE study group $\mathrm{I}: \chi^{2}=1.83, \mathrm{p}=0.18$ (Hardy-Weinberg equilibrium)

HWE control group I: $\chi^{2}=4.80, p=0.06$

[19]. A similar conclusion was drawn by Mlynarski et al., who examined 520 T1DM patients (DKD was diagnosed in T1DM patients with UACR $>250 \mathrm{mg} / \mathrm{g}$ in men and UACR > $355 \mathrm{mg} / \mathrm{g}$ in women) in comparison with 320 controls [T1DM patients having DM for at least 15 years and with UACR $<17 \mathrm{mg} / \mathrm{g}$ (men) or $<25 \mathrm{mg} / \mathrm{g}$ (women)] and concluded that the CCR5 gene polymorphism $(\mathrm{rs} 1799987,59029 \mathrm{~A} / \mathrm{G})$ was associated with DKD, i.e. A allele carriers had significantly higher risk of developing DKD, but it was limited to male patients [15].

There have also been other European studies concerning CCR5 gene polymorphism and DKD. For example, Yang et al. performed an analysis on a group of 260 British Caucasian patients with T1DM and 104 controls, examining the same SNP as we did. The results obtained by Yang et al. differ slightly from those presented by Mlynarski et al. [15]; in the British population the presence of A allele and AA genotype was associated only with the presence of T1DM itself but not with DKD. Moreover, as far as DKD's presence was concerned, there was only a trend without statistical significance, indicating that the presence of the GG genotype (contrary to A allele proposed by Mlynarski et al. [15]) might be of consequence for developing this microvascular complication of diabetes [14].

59029 A/G CCR5 gene polymorphism was also the subject of research on other continents, but there is no consistency in terms of which allele and genotype predispose to DKD [14, 15, 20-23, 30]. GG genotype and the presence of G allele of 59029 A/G CCR5 gene polymorphism was significantly more prevalent in Caucasian patients of Turkish origin with DM, atherosclerosis, and with ESRD undergoing haemodialysis, which was proven in the study by Bagci et al. Their study included 225 patients on renal replacement therapy and 201 healthy controls [20]. G allele of 59029 A/G CCR5 gene polymorphism also turned out to be significantly associated with DKD in a subgroup of 203 Chinese T2DM patients with impaired renal function in a trial conducted by Yahya et al. among a multicultural group of Malaysian, Chinese, and
Table 4. Distribution of the genotype frequencies of the CCR5 gene polymorphism (rs1799987, 59029 A/G) in the study and control groups II ( $p=0.3$ on the basis of $\chi^{2}$ Pearson's test)

\begin{tabular}{lcc}
\hline Variable & $\begin{array}{c}\text { Study group II } \\
\text { (n = 105) }\end{array}$ & $\begin{array}{c}\text { Control group II } \\
\text { (n = 166) }\end{array}$ \\
\hline AA genotype [n (\%)] & $48(45.7)$ & $61(36.8)$ \\
\hline AG genotype [n (\%)] & $41(39.1)$ & $73(44.0)$ \\
\hline GG genotype [n (\%)] & $16(15.3)$ & $32(19.3)$ \\
\hline
\end{tabular}

Data presented as numbers of patients (percentages)

HWE study group II: $\chi^{2}=2.03, \mathrm{p}=0.15$

HWE control group II: $\chi^{2}=1.43, p=0.23$

Indian subjects. Conversely, on the basis of data from India (417 T2DM patients and 197 healthy controls), Yadav et al. concluded that AA genotype and A allele were significantly more frequent both in subjects with T2DM compared to healthy controls and in patients with DKD (understood as the presence of diabetic retinopathy, eGFR $<60 \mathrm{~mL} / \mathrm{min} / 1.73 \mathrm{~m}^{2}$, and proteinuria $>500 \mathrm{mg} /$ day for at least 3 months) compared to T2DM patients without renal complications [22]. Convergent conclusions were drawn by Prasad et al., who observed in a group of Indian T2DM patients (196 with DKD and 225 without) a significant association of the presence of allele A and chronic renal insufficiency (serum creatinine $\geq 3.0 \mathrm{mg} / \mathrm{dL}$ ) [30]. Similarily, Mokubo et al. revealed that the CCR5 59029A(+) genotype showed an independent positive correlation with the onset or progression of DKD on the basis of the observation of almost 200 Japanese T2DM patients [23].

Several meta-analyses were performed to verify the association between the 59029 A/G CCR5 gene polymorphism and risk of DKD [31-34]. Two of them focused only on the same SNP as examined in our study, i.e. 59029A/G polymorphism of CCR5 gene [31, 34], and in others our SNP was 1 in 55 [33] or 1 in 443 [32] analysed genetic variants. Cao et al. concluded that CCR5 gene promoter polymorphism (rs1799987, 59029 A/G) was significantly related to greater susceptibility to DKD, especially among Asian patients with T2DM [31]. Zhang et al., on the basis of their meta-analysis, indicated that this $\mathrm{SNP}^{\prime}$ s polymorphism (i.e. CCR5 gene promoter polymorphism [rs1799987, 59029 A/G]) might affect individual susceptibility to microangiopathic complications of diabetes [34]. Meta-analysis results of Nazir et al. suggest that among several examined polymorphisms, CCR5 gene polymorphism showed a significant positive association and protective effect in DKD[33]. Tziastoudi et al. conducted a meta-analysis of genetic association studies for the role of inflammation and the immune system in DKD, on the basis of which CCR5 gene polymorphism turned out to be associated with an increased risk of DKD, but the authors empha- 
size that the presented results should be interpreted cautiously because the number of conducted studies was not large enough to draw unequivocal and certain conclusions [32].

Because the results of our study are in contradiction with most of the research conducted in this topic so far, it is worth considering the possible explanation for this phenomenon and a good occasion to rethink the ongoing question of why not every patient with diabetes develops vascular complications. One of the theories indicates that it is due to genetic predisposition (clustering in families, concordance in twins, data from genome-wide association studies) [35]. Unfortunately, from the present evidence, we still cannot state that a certain genotype can protect individuals from developing complications in the case of uncontrolled disease and unfavourable environmental factors. The latter constitute another direction of research on the development of complications, which are understood not only as personal behavioural contributions (i.e. lifestyle behaviours such as inadequate nutrition, low physical activity, sleep deprivation, smoking, and alcohol consumption) but also social ones (interpersonal, occupational, and psychological factors) and natural environment (toxins, green spaces, noise and air pollution) [36]. However, there is no certain evidence that specific characteristics of the patients' environment might protect them from diabetes complications independently of genotype in the case of uncontrolled glycaemia. The only factor so far that has proven protective effect in relation to the occurrence and progression of complications is the proper treatment to target with an appropriate combination of drugs $[37,38]$. It might be that patients in our study were different from other populations examined to date in terms of drugs used and the metabolic control obtained, which is why the outcomes differ.

The results of the presented study are negative, but this does not diminish their value, because negative studies are of great importance in medicine and especially in genetics, because they indicate the directions for further studies [39]. The limitation of the study, which should be acknowledged, is the relatively small sample size and the fact that only one SNP was examined. On the other hand, we used two available definitions of DKD, which ensures the proper selection of study participants.

\section{Conclusions}

The presented study did not confirm the association between CCR5 gene promoter polymorphism 59029 A/G (rs1799987) and the risk of DKD patients with T2DM, represented by almost 500 of them living in the Upper Silesia Region.
The results of our study contradict other analyses performed in groups of Polish patients with DM; therefore, further studies in this area are needed in order to establish or explicitly exclude this association.

\section{Funding}

Statutory work of Silesian Medical University.

\section{References}

1. Alicic RZ, Rooney MT, Tuttle KR. Diabetic Kidney Disease: Challenges, Progress, and Possibilities. Clin J Am Soc Nephrol. 2017; 12(12): 2032-2045, doi: 10.2215/CJN.11491116, indexed in Pubmed: 28522654.

2. Persson F, Rossing P. Diagnosis of diabetic kidney disease: state of the art and future perspective. Kidney Int Suppl (2011). 2018; 8(1): 2-7, doi: 10.1016/j.kisu.2017.10.003, indexed in Pubmed: 30675433.

3. Matoba K, Takeda Y, Nagai Y, et al. Unraveling the Role of Inflammation in the Pathogenesis of Diabetic Kidney Disease. Int J Mol Sci. 2019; 20(14), doi: 10.3390/ijms20143393, indexed in Pubmed: 31295940.

4. Zheng Z, Zheng F. Immune Cells and Inflammation in Diabetic Nephropathy. J Diabetes Res. 2016; 2016: 1841690, doi: 10.1155/2016/1841690, indexed in Pubmed: 26824038.

5. Tesch GH. Diabetic nephropathy - is this an immune disorder? Clin Sci (Lond). 2017; 131(16): 2183-2199, doi: 10.1042/CS20160636, indexed in Pubmed: 28760771.

6. Cavalera M, Frangogiannis NG. Targeting the chemokines in cardiac repair. Curr Pharm Des. 2014; 20(12): 1971-1979, doi: 10.2174/13816128 113199990449, indexed in Pubmed: 23844733.

7. Oppermann M. Chemokine receptor CCR5: insights into structure, function, and regulation. Cell Signal. 2004; 16(11): 1201-1210, doi: 10.1016/j. cellsig.2004.04.007, indexed in Pubmed: 15337520.

8. Oo Z, Barrios CS, Castillo L, et al. High levels of CC-chemokine expression and downregulated levels of CCR5 during HIV-1/HTLV-1 and HIV-1/HTLV-2 coinfections. J Med Virol. 2015; 87(5): 790-797, doi: 10.1002/jmv.24070, indexed in Pubmed: 25678365

9. Leach K, Charlton SJ, Strange PG. Analysis of second messenger pathways stimulated by different chemokines acting at the chemokine receptor CCR5. Biochem Pharmacol. 2007; 74(6): 881-890, doi: 10.1016/j. bcp.2007.06.019, indexed in Pubmed: 17645873 .

10. Jin J, Colin P, Staropoli I, et al. Targeting spare CC chemokine receptor 5 (CCR5) as a principle to inhibit HIV-1 entry. J Biol Chem. 2014; 289(27): 19042-19052, doi: 10.1074/jbc.M114.559831, indexed in Pubmed: 24855645.

11. Navratilova Z. Polymorphisms in CCL2\&CCL5 chemokines/chemokine receptors genes and their association with diseases. Biomed Pap Med Fac Univ Palacky Olomouc Czech Repub. 2006; 150(2): 191-204, doi: 10.5507/bp.2006.028, indexed in Pubmed: 17426779.

12. Martinson JJ, Chapman NH, Rees DC, et al. Global distribution of the CCR5 gene 32-basepair deletion. Nat Genet. 1997; 16(1): 100-103, doi: 10.1038/ng0597-100, indexed in Pubmed: 9140404.

13. Blanpain C, Libert F, Vassart G, et al. CCR5 and HIV Infection. Recept Channels. 2011; 8(1): 19-31, doi: 10.3109/10606820212135, indexed in Pubmed: 12402506

14. Yang B, Houlberg K, Millward A, et al. Polymorphisms of chemokine and chemokine receptor genes in Type 1 diabetes mellitus and its complications. Cytokine. 2004; 26(3): 114-121, doi: 10.1016/j.cyto.2004.01.005, indexed in Pubmed: 15135805.

15. Mlynarski WM, Placha GP, Wolkow PP, et al. Risk of diabetic nephropathy in type 1 diabetes is associated with functional polymorphisms in RANTES receptor gene (CCR5): a sex-specific effect. Diabetes. 2005; 54(11): 3331-3335, doi: 10.2337/diabetes.54.11.3331, indexed in Pubmed: 16249462.

16. Pettigrew KA, McKnight AJ, Patterson CC, et al. Resequencing of the CCL5 and CCR5 genes and investigation of variants for association with diabetic nephropathy. J Hum Genet. 2010; 55(4): 248-251, doi: 10.1038/jhg.2010.15, indexed in Pubmed: 20203694.

17. Nakajima K, Tanaka $Y$, Nomiyama T, et al. RANTES promoter genotype is associated with diabetic nephropathy in type 2 diabetic subjects. Diabetes Care. 2003; 26(3): 892-898, doi: 10.2337/diacare.26.3.892, indexed in Pubmed: 12610055.

18. Ahluwalia TS, Khullar M, Ahuja M, et al. Common variants of inflammatory cytokine genes are associated with risk of nephropathy in type 2 diabetes among Asian Indians. PLoS One. 2009; 4(4): e5168, doi: 10.1371/journal.pone.0005168, indexed in Pubmed: 19357773.

19. Buraczynska M, Zukowski P, Wacinski P, et al. Chemotactic cytokine receptor 5 gene polymorphism: relevance to microvascular complications in type 2 diabetes. Cytokine. 2012; 58(2): 213-217, doi: 10.1016/j. cyto.2012.01.007, indexed in Pubmed: 22325341. 
20. Bagci B, Bagci G, Huzmeli C, et al. Associations of fractalkine recepto (CX3CR1) and CCR5 gene variants with hypertension, diabetes and atherosclerosis in chronic renal failure patients undergoing hemodialysis. In Urol Nephrol. 2016; 48(7): 1163-1170, doi: 10.1007/s11255-016-1293-0, indexed in Pubmed: 27118566.

21. Yahya MJ, Ismail PB, Nordin NB, et al. Association of CCL2, CCR5, ELMO1, and IL8 Polymorphism with Diabetic Nephropathy in Malaysian Type 2 Diabetic Patients. Int J Chronic Dis. 2019; 2019: 2053015, doi: 10.1155/2019/2053015, indexed in Pubmed: 30713847.

22. Yadav AK, Kumar V, Dutta P, et al. Variations in CCR5, but not HFE, ELMO1, or SLC12A3, are associated with susceptibility to kidney disease in north Indian individuals with type 2 diabetes. J Diabetes. 2014; 6(6): 547-555, doi: 10.1111/1753-0407.12128, indexed in Pubmed: 24433479.

23. Mokubo A, Tanaka Y, Nakajima K, et al. Chemotactic cytokine receptor 5 (CCR5) gene promoter polymorphism $(59029 \mathrm{~A} / \mathrm{G})$ is associated with diabetic nephropathy in Japanese patients with type 2 diabetes: a 10-year longitudinal study. Diabetes Res Clin Pract. 2006; 73(1): 89-94, doi: 10.1016/j.diabres.2005.12.006, indexed in Pubmed: 16442182.

24. Kwiendacz H, Nabrdalik K, Adamczyk P, et al. Association of single nucleotide polymorphism (rs741301) of the ELMO1 gene with diabetic kidney disease in Polish patients with type 2 diabetes: a pilot study. Endokrynol Pol. 2020; 71(1): 66-72, doi: 10.5603/EP.a2019.0066, indexed in Pubmed: 31909452.

25. Cunningham A, Benediktsson $\mathrm{H}$, Muruve DA, et al. Trends in Biopsy-Based Diagnosis of Kidney Disease: A Population Study. Can J Kidney Health Dis. 2018; 5: 2054358118799690, doi: 10.1177/2054358118799690 indexed in Pubmed: 30263130.

26. Lorenzo-Medina M, De-La-Iglesia S, Ropero P, et al. Effect of hemoglobin Porto Alegre on glycated hemoglobin $(\mathrm{HbA}(1 \mathrm{c}))$ measurement with the HA-8160 high performance liquid chromatography method. Clin Chem Lab Med. 2013; 51(10): e247-e249, doi: 10.1515/cclm-2013-0049, indexed in Pubmed: 23612667.

27. Delanghe JR, Speeckaert MM. Creatinine determination according to Jaffe-what does it stand for? NDT Plus. 2011; 4(2): 83-86, doi: 10.1093/ndtplus/sfq211, indexed in Pubmed: 25984118.

28. Shahbaz H, Gupta M. Creatinine Clearance. StatPearls Publishing, Treasure Island 2021: StatPearls.

29. McKnight AJ, Woodman AM, Parkkonen M, et al. Warren 3/UK GoKinD Study Group. Investigation of DNA polymorphisms in SMAD genes for genetic predisposition to diabetic nephropathy in patients with type 1 diabetes mellitus. Diabetologia. 2009; 52(5): 844-849, doi: 10.1007/s00125-009-1281-3, indexed in Pubmed: 19247629.

30. Prasad P, Tiwari AK, Kumar KM, et al. Association of TGFbeta1, TN Falpha, CCR2 and CCR5 gene polymorphisms in type-2 diabetes and renal insufficiency among Asian Indians. BMC Med Genet. 2007; 8: 20, doi: 10.1186/1471-2350-8-20, indexed in Pubmed: 17428349.

31. Cao M, Tian Z, Zhang L, et al. Effects of 59029G/A polymorphism on the risk to diabetic nephropathy. Oncotarget. 2017; 8(63): 106926-106934, doi: 10.18632/oncotarget.22148, indexed in Pubmed: 29291000.

32. Tziastoudi M, Stefanidis I, Hadjigeorgiou GM, et al. A systematic review and meta-analysis of genetic association studies for the role of inflammation and the immune system in diabetic nephropathy. Clin Kidney J. 2017; 10(3): 293-300, doi: 10.1093/ckj/sfx008, indexed in Pubmed: 28616206.

33. Nazir N, Siddiqui K, Al-Qasim S, et al. Meta-analysis of diabetic nephropathy associated genetic variants in inflammation and angiogenesis involved in different biochemical pathways. BMC Med Genet. 2014 15: 103, doi: 10.1186/s12881-014-0103-8, indexed in Pubmed: 25280384.

34. Zhang Z, Zhang X, Dong J, et al. Association of chemokine ligand $5 /$ chemokine receptor 5 gene promoter polymorphisms with diabetic microvascular complications: A meta-analysis. J Diabetes Investig. 2016 7(2): 212-218, doi: 10.1111/jdi.12397, indexed in Pubmed: 27042273.

35. Fuchsberger C, Flannick J, Teslovich TM, et al. The genetic architecture of type 2 diabetes. Nature. 2016; 536(7614): 41-47, doi: 10.1038/nature18642, indexed in Pubmed: 27398621.

36. Bhatnagar A. Environmental Determinants of Cardiovascular Disease. Circ Res. 2017; 121(2): 162-180, doi: 10.1161/CIRCRESAHA.117.306458, indexed in Pubmed: 28684622.

37. Marx N, Davies M, Grant P, et al. Guideline recommendations and the positioning of newer drugs in type 2 diabetes care. Lancet Diabetes Endocrinol. 2021; 9(1): 46-52, doi: 10.1016/s2213-8587(20)30343-0, indexed in Pubmed: 33159841.

38. Petrie JR, Guzik TJ, Touyz RM. Diabetes, Hypertension, and Cardiovascular Disease: Clinical Insights and Vascular Mechanisms. Can J Cardiol. 2018; 34(5): 575-584, doi: 10.1016/j.cjca.2017.12.005, indexed in Pubmed: 29459239.

39. Matosin N, Frank E, Engel M, et al. Negativity towards negative results: a discussion of the disconnect between scientific worth and scientific culture. Dis Model Mech. 2014; 7(2): 171-173, doi: 10.1242/dmm.015123, indexed in Pubmed: 24713271 